\title{
The Peculiarities of the Advanced Training of the Future Specialists for the Competitive High-Tech Industry in the Process of Integration of Education, Science and Industry
}

\author{
Albina R. Shaidullina \\ Almetyevsk State Oil Institute, 423450, Almetyevsk, Russia \\ E-mail: albina-plus@mail.ru \\ Shamil F. Sheymardanov \\ Kazan (Volga region) Federal University, 420008, Kazan, Russia \\ Yoldyz N. Ganieva \\ Institute of Technology Branch of Ulyanovsk State Agricultural Academy named after P.A. Stolypin, 433511, Dimitrovgrad, Russia \\ Sergey A. Yakovlev \\ Ulyanovsk State Agricultural Academy named after P.A. Stolypin, 432017, Ulyanovsk, Russia \\ Elmira R. Khairullina \\ Kazan National Research Technological University, 420015, Kazan, Russia \\ Milyausha K. Biktemirova \\ Kazan (Volga region) Federal University, 420008, Kazan, Russia \\ Ilana B. Kashirina \\ Amur State University, 675027, Blagoveschensk, Russia \\ Doi:10.5901/mjss.2015.v6n2s3p43

\section{Abstract} \\ The urgency of the advanced professional training of the future competitive specialists for a high-tech industry is conditioned by \\ the fact that one of the strategic objectives of modern production is to provide a new generation with the manpower, the leaders \\ of production who can not only purchase and adapt foreign models, but also but have the qualification to develop and introduce \\ new home-produced samples, and also be able to quickly adapt to new social and economic conditions. Therefore, this article \\ aims to identify the features of the advanced training of the future specialists for high-tech industry in the process of integration \\ of education, science and industry. The authors have found the distinctive features of the institution providing the advanced \\ training of the future competitive specialists; proposed measures for the development of advanced training; set the \\ requirements to the syllabus and technology of advanced training; discussed the conditions for the implementation of the \\ advanced training of the future competitive specialists in the condition of education, science and industry integration. The \\ issues of this article are of both theoretical and practical value for the management and teaching staff of the vocational \\ education institutions.
}

Keywords: advanced training; integration; education; science; high-tech industry; future specialists.

\section{Introduction}

General globalization leads to understanding the significant role of education and science in the development of modern society - the subject of the demand for a scientific result is not the industry but the education system. The system of education is where the intelligence of the community is built up - the most important resource, but the statistics show that 
only a few percent of the scientific inventions and background knowledge of science is directly introduced into practice. Their main consumer is education. Absorbing scientific knowledge in the educational process the youth brings it into practical activities of the society, and in a highly competitive environment only 6 - 8 percent of the research is transformed into a new product or process (Erofeev et al., 2007; Ivanov et al., 2015; Shaidullina et al., 2015).

For the innovative mode of the economy development in Russia there are some necessary preconditions, namely: developed science, advanced production and technical capacity, and a good educational system. For example, advanced methods of vocational training development allowing to background the innovative projects and "breakthrough technology" in the industry have already proven themselves in the USSR high-tech innovation projects (uranium and rocket and space industry) (Moses and Burlyukina, 2007).

The urgency of the problem comes from the fact that, firstly, there is a constant updating of scientific and technical information, and secondly, there is a burning need for information not only about the past and present but also about the future and from the future when you need to make a decision basing on a set of exploratory and intended forecasts (Sakhieva et al., 2015. Consequently, the education system is facing dramatic changes at all levels with its transition to problem-based teaching that approach the practical needs of a modern economy where advanced vocational training of the future professionals is a major preventive measure for their adaptation and social protection.

\section{Literature Review}

The greatest scientific disagreements occur on the subject of advance, i.e. about the syllabus of the advanced education. Firstly, it seems natural to anticipate in education the changes in science, technology and social life that are most likely to occur in the near (or distant) future. However, the reality is that even a scientific forecast basing on a thorough analysis of the phenomena and development trends, unfortunately, in practice can fail badly. Moreover, it has been established that different methods often bring to diametrically contrary results at the stage of forecast. It is apparent what challenges the educational science faces when trying to build a model of the syllabus which will be demanded in a few years. "You cannot give the student the knowledge about laws, regularities, categories of nature and society that are scientifically unfounded. You can not reveal the operation principles of the techniques and technologies that have not yet been discovered (Novikov, 1998). Therefore, the principle of advancing from the "bottom", starting from a specific syllabus can be justified only in a limited number of educational systems and practices: when we are talking about the particular syllabus and a high probability of its demand from a particular cohort of students (career enhancement focused on the development of new technologies, retraining specialties with an obviously growing demand in the economy, studying foreign languages and information technology "for the future"; adaptive training of the convicts enduring the punishment, etc.).

The approach that seems deeper and more interesting from a scientific point of view and practically promising (albeit with a delayed effect) is the approach to advanced education "from above" shared by the majority of scientists dealing with this issue. Here, the fundamental elements of the advanced educational syllabus consider not the specific knowledge and skills but the general characteristics of an educated person, such as the development of general abilities, aptitudes, interests, and beliefs that contribute to human adaptation to changing life (Bim-Bad, 1998); the ability to use this knowledge to improve the activities (A.R. Shaidullina); the development of students' personality (Novikov, 2000; Levina, et al, 2015; Merzon, et al, 2015); basic general knowledge as well as ideological knowledge (Podobed and Maron, 2009); development of creative abilities, independent learning skills, the abilities to find solutions to complex problems (L.V. Zanin and others). The advanced education ultimately promotes the establishment of global, noospheric consciousness, "responsible mind" that can fathom the impending danger and does everything to prevent it (Subetto, 1998, 2000; Ursul, 2008, 2005).

However, the scientific study of the advanced education problem is currently carried out only at a general conceptual level. At the same time it applies to either the education system as a whole or school and vocational education in particular. The problem of advanced education of adults as such has still not been explored.

\section{Methodological Framework}

The very idea of advanced vocational education as an essential mechanism of the integration of education and production lies in the development of personal capabilities to define himself in the world of profession and his training for the rapidly changing production and sociosphere. The intensification of the advanced professional education, the degree of its manifestations also become prerequisite for the development of production due to the higher general and professional readiness of the possible applicants for certain vacancies, which makes the problem of training and 
retraining for the ever-growing production less urgent.

Certainly, the education market is now increasingly appreciating not only highly skilled, but also erudite persons who can "extract" the necessary knowledge themselves and generate the new one easily. Particularly such all-around personalities bring to their firms the greatest profit, and therefore are highly- demanded in the labor market. These graduates can be called elite and be educated within the selected training course - a special system of teaching process and research work (Manuilov and Fedorov, 2002). Such training can be and is likely to be implemented not only in the elite, but any university that can concentrate the necessary resources within one or more areas of vocational training fields for the selected training.

In order to qualify the competitive highly-demanded professionals responsible for their own and corporate success the mechanisms of structuring the educational trajectories and curriculum, the implementation of the educational technologies should be aimed at the development of four major characteristics of an innovative personality: creativity, communication, competence and competencies (Lobatskaya, 2007). Meanwhile, one should be aware that for the different types and fields of innovation activities the correlation of the four " $\mathrm{C}$ " should take into account the level and susceptibility to one or another creative activity, that is, the natural creativity of the person:

- for the students who are prone to technical creativity (creative and innovative personality), capable of creating a new product and bring it to a final demand and assess the creations of other people who have the ability and desire to bring this product to implementation the educational vector must be focused on acquiring and developing communicative competence. The areas of demand for the professionals with highly-creative and innovative abilities are the applied science, education, production and business, and the specialty fades into insignificance;

- for the students who are prone to scientific creativity (innovation and creative personality) the educational vector should be focused on acquiring competence and developing creative abilities. These professionals will be in demand mostly in fundamental science and education, the institutions with a creative focus (Fayzullina and Saglam, 2014; Mrathuzina, et al, 2015);

-for the students who are prone to public social activities (public innovative personality), the educational vector should be focused on the acquisition and development of the communicative competence. These professionals will join the ranks of politicians, public figures, humanitarians of all areas involved in the social and political institutions;

-for the students who are prone to organizational performance (organizational and innovative personality) the educational vector must be directed towards the competencies and developing their own innovative creativity. These specialists will go the straightest way to business and production where they will take the role of reformers capable of giving boost to production / business to a high level and make any enterprise the industry leader.

The consideration of these models suggests that they fully correspond the existing social order for an innovative personality as the basis for a society developing through innovative technologies. The author offers the challenge of developing the national-level approaches to the designing of the educational programs on the basis of the individual training plans. However, to implement such a far-reaching goal it is necessary to provide the appropriate intellectual capacities as intelligence creates intelligence, and it requires certain conditions for its own reproduction that are in contradiction with the fact that the state funds education three times less compared to the Soviet times expecting more return than 30 years ago. Uneager to be left behind the developed countries the Russian state and society spend 10 times less per student than those countries and expect the results get higher (Plaksiy, 2005). Therefore, this work can be carried out in the elite university which will lead to the situation when "non-leading" universities will lose the opportunity to unlock the potential of the promising youth. The above-mentioned factors show that such education will be available only for a small part of population and will not bring Russia to the strategic objective associated with the creation of mass, high-quality, affordable and effective higher education the main objective of which is to provide the production with qualified personnel who can improve it in the post-crisis period.

It should also be mentioned that the establishment of the elite universities occurs mainly in the capital cities that are geographically distant from the enterprises. Many regional universities were established as technical colleges at the basic enterprises and have accumulated a sufficient experience and valuable links between educational institutions and industry the loss of which will affect the efficiency of these enterprises.

\section{Results and Discussions}

\subsection{The particularities of an educational institution providing the advanced training courses}

The main features of the institution conducting the advanced training of the specialists for high-tech industries are: - Innovative education on the basis of a unitary training and research process with the use of interdisciplinary 
problem- and project-oriented educational technologies;

- A system of the selected training of the specialists on the basis of the scientific schools;

- The integration of science, education and innovation;

- The established corporate culture and internal competitive environment of the university;

- The organizational structure relevant to the new tasks and methods of managing the educational institution based on the government and public management and autonomy;

- the developed infrastructure of interaction between the educational institutions and Russian and foreign environment.

\subsection{The measures for the development of the advanced training system}

The main goal of advanced training is to help the businesses survive the economic crisis, maintain the personnel and prepare them for the post-crisis innovation economy. To achieve this many regions of Russia have introduced a series of actions for the development of advanced training including:

- The development of a system to collect and analyze information about the need of enterprises and organizations in the advanced training opportunities and provision with the educational services required by the educational institutions;

- Improving long-term forecast for the balance between manpower and personnel demand with a due regard to the priorities of the Concept of the long-term socio-economic development up to 2020, including the appropriate areas for the advanced vocational training;

- Implementation of the order of development and certification of the professional educational programs to meet the employers' requirements within the uniform methodology (competence approach, modular design, innovative educational technology);

- Creating the infrastructure programs of the additional vocational education for the advanced training with various time scales to achieve the results at the educational institutions of various levels involving the resources of the industrial enterprises and organizations, business structures, research institutions;

- Introduction of the process monitoring and quality control of the results of the advanced training;

- Creating the infrastructure and the development of the regulatory framework of the regional certification system of professional qualifications (competencies).

\subsection{The requirements for the advanced training syllabus}

The idea of advanced education is to form a new human consciousness that will outpace the present, as for the advanced training of the technical specialist the traditional understanding of vocational education as mastering a certain amount of knowledge acquired through teaching particular subjects is clearly insufficient. Moreover, it is a significant drag on the ways in forming a new style of thinking of an engineer. The basis for the advanced education should become not the academic subjects but also the ways of thinking and acting, that is the procedures of reflective nature. Knowledge, methods of cognition and activities must be connected into the organic integrity.

Restructuring the training syllabus requires above all the fundamentalization of the education syllabus, formation of the innovative thinking and specialized training to transfer the technologies. These requirements equally apply to the research, design and entrepreneurship training.

Fundamentalization of the education syllabus can be achieved by broadening and deepening the interdisciplinary knowledge focused on problem solving in scientific, design and entrepreneurship activities; increasing the level of proficiency in cognitive, professional, communicative and axiological activities; providing the synthesis of the science and humanities and transition to the complex criteria of productivity, efficiency and work quality; the ability to develop the scientific basis of the social and professional activities by means of methodologization, generalization and different kinds of modeling (Chitalin, 2000).

\subsection{The requirements for the advanced training technologies}

The important issues of the advanced education are the teaching material and educational technologies creating the conditions for the development of the innovative thinking: multi-criteria problem statement and solution, nonlinear thinking, sustainable skills of possessing information culture and others.

Any modern high-tech production is characterized by the development of modern technology of information 
accumulation and transfer; the development of new microelectronic technology and modern means of automation, improving the automated controls that allow to dramatically increase the competitiveness and efficiency of domestic production; the development of laser technology, new methods of processing materials; the transition from the conveyor mass production to the flexible automated one; the improvement of security as a complex character of the man-machine systems in the unity of technical, socio-psychological, cultural and ethical aspects; overcoming the ecologic limitations through the integration of production and nature restoration processes into a single process. Consequently, the modern enterprises together with the educational institutions should be actively involved in the training of technical specialists for high-tech industries, as training of the specialists only in the walls of the institution is not possible, because they need specific practices and a large amount of practical training.

In this regard, the high-end technologies of education become the new scientific and methodical focus of didactics and their principal difference becomes the sign of advanced training, research and methodological activities as "pedagogical reconnaissance." In other words, the high-end training technologies are the creation of " design and experimental patterns" in the field of education and demonstration of their effectiveness as benchmarking.

The principles of high-end training technologies are: compliance of the advanced education technology with the modern sanitary and technical standards, noncontradiction to the humane and moral objectives of the education of the society, efficiency and democratic character of education with opportunities for the general population to get education (Pokholkov, 2003).

In this regard, it is necessary to develop a new approach to technical education since the first year of education in university, and show the students the relevance of the proposed educational material to their future engineering activity, prospects of the technological, economic and social development of the community. This teaching method allows the students to develop the motivation to study that is so much needed, a greater receptivity to the theory while developing it through practice.

One of the promising methods used in the advanced technical education is "context teaching " when the motivation for knowledge assimilation is achieved by building relationships between the specific knowledge and its application. This method is quite effective, as the aspect of application for students is crucial. Equally important is the "learning from experience" when the students have an opportunity to associate their own experience with the subject of the study. These methods are considered active learning methods, since the focus is on the students' acquiring knowledge through various activities and on the basis of experience.

The problem-oriented approach to education allows students to focus on the analysis and solution of any particular problematic situation that becomes the starting point in the learning process. It is sometimes important to not only solve the problem but to put and articulate it correctly. The problematic situation motivates the students to consciously acquire knowledge necessary to solve it. The interdisciplinary approach to learning allows to teach students to get knowledge from different fields by themselves, to group them and focus in the context of the specific problem to be solved.

Another effective and promising way is to use the so-called «case-study» methods based on the analysis of trueto-life situations from engineering practice, management, organization of production and further developing relevant ideas and solutions.

It is important in the advanced training of technical specialists to apply the project technologies of training in a work-team (targeted, role, creative groups). This creates conditions that closely follow the real engineering, and thus, the students gain experience in solving the complex problem of engineering design with the roles distribution and responsibilities between the team members.

To correlate the training of the technical specialists with the production requirements it is necessary to optimally adjust the activities of the university or college that should be carried out at a regular intervals in connection with the production and in turn would provide:

- The possibility of writing the term papers and graduate studies at the enterprise;

- A combination of education and production activities, classroom training and practical work in the offices, manufacturing workshops;

- A certain control over the trainees by the company's management which encourages responsibility, integrity, conscientiousness of the students' learning activities;

- Encouraging the active learners, attracting them to work in groups of experts for possible employment.

\subsection{The terms of the advanced vocational education}

The conditions for the advanced vocational training are the following: the readiness and active participation of the teaching staff in the innovation activities of the vocational education institution; the integration of the research, education 
and innovation; a corporate culture and internal competition within a vocational educational institution ; the organizational structure that corresponds the new tasks and methods of managing educational institutions basing on a combination of public, government and public administration and autonomy; the developed infrastructure of interaction between the educational institutions and Russian and foreign environment; updating the content on the basis of the world's information resources; integration of the entrepreneurial ideas in the courses syllabi; the use of interdisciplinary problem-and projectoriented educational technologies; the rating system improvement and others.

\section{Conclusions}

The advanced training of the specialists able to effectively implement the innovative projects is the objective of the national Russian priorities where the utmost importance should be given to the following:

- it is necessary to sustain the continuity of the traditional approach in the national system of training of the future engineers which has a deep tradition and undoubted successes in designing the advanced engineering education;

- $\quad$ there emerged a need for a modern model of the advanced education with remarkable changes at all levels with the transition to problem-based teaching closer to the practical needs of a modern economy where the advanced vocational training of the future professionals is a major preventive measure for their adaptation and social protection;

- the important constituents of the advanced education syllabus should become the teaching material and educational technologies creating conditions for the development of the innovative thinking with a high level of methodological culture;

- in order to accomplish the innovative projects it is necessary to provide greater integration of science, education and industry and corresponding intellectual capacity.

\section{References}

Erofeev G.V., Pankin A.S., Hooks Y.Y. (2007). New approaches to engineering education. Engineering Education, 4, 58-63.

Fayzullina, A.R. Saglam, F.A.(2014). Methods and forms of organization of training activities on the lessons of history. History teaching in school. 9, 45-50.

Levina Elena Y., Mustafina Gulshat M., Nigmetzyanova Venera M., Galiyev Radik M., Chalkina Natalya A.. Improving the Information System of University Management. Review of European Studies, 7(1), 109-116.

Merzon, E.E., Fayzullina, A.R., Ibatullin, R.R., Krylov, D.A., Schepkina, N. K., Pavlushkina, T.V. (2015) Organizational and pedagogical conditions of academic mobility development of students at school of higher professional education. Review of European Studies, 7(1), 46-51.

Moses V.B., Burlyukina E.V. (2007). An innovative model of training for specialists on demand. Engineering Education, 4, 20-27.

Mrathuzina, G.F., Fayzullina, A.R., Saglam, F.A. (2015) Substantive, Methodological and Organizational Discourse in Oriental History Learning at School and University. Review of European Studies, 7(1), 57-62

Novikov A.M. (1998). Principles of the system of continuing professional education. Pedagogy, 3, 11.

Novikov A.M. (2000). The methodology of education. Moscow, 320.

Ursul A. (2008). Principle of temporal integrity and education. Bulletin of higher education, 3, 28-35.

Ursul A. (2005). Russian education for sustainable development: the first steps in the future. Bulletin of the Higher School, 8, 3-11.

Subetto A.I. (2000). Quality of Continuing Education in the Russian Federation: Status, Trends, Problems and Prospects (monitoring experience. Saint Petersburg, 498.

Subetto A.I. (1998). Methodology standardization of continuous-education: problems and ways to solve them. Moscow, 70.

Manuilov V.F., Fedorov I.V. (2002). Problems of formation of an elite training in the field of engineering and technology. Innovations in Higher Technical School of Russia, Vol. 1.

Lobatskaya R.M. (2007). Formation of innovative personality as one of the problems of advancing innovative education. Engineering Education, 4, 52-57.

Plaksiy S. (2005). Intelligence flows to where it is appreciated and stimulate. Questions of high school, 10, 10-12.

Chitalin N.A. (2000). Fundamental vocational education. Vocational education, 2, 11-15.

Pokholkov Yu. (2003). Problems and main directions of improving engineering education. Bulletin of higher education,10, 3-8.

Bim-Bad B.M. (1998). Pedagogical anthropology DOC. Moscow, 576.

Podobed V.I., Maron A.E. (2009). Practical andragogics. Advance adult education. Saint Petersburg, 234.

Ivanov V.G., Shaidullina A.R., Drovnikov A.S., Yakovlev S.A. \& Masalimova A.R. (2015). Regional Experience of Students' Innovative and Entrepreneurial Competence Forming. Asian Social Science, Vol. 11, No. 1, 35-40, doi:10.5539/res.v7n1p35.

Shaidullina A.R., Krylov D.A., Sadovaya V.V., Yunusova G.R., Glebov S.O., Masalimova A.R. \& Korshunova I.V. (2015). Model of Vocational School, High School and Manufacture Integration in the Regional System of Professional Education. Review of 
European Studies, Vol. 7, No. 1, 63-67, doi:10.5539/res.v7n1p63.

Sakhieva R.G., Khairullina E.R., Khisamiyeva L.G., Valeyeva N.S., Masalimova A.R., Zakirova V.G. (2015). Designing a Structure of the Modular Competence-Based Curriculum and Technologies for Its Implementation into Higher Vocational Institutions. Asian Social Science; Vol. 11, No. 2, 246-251, doi:10.5539/ass.v11n2p246 